\title{
Two-Phase Transplantation (TPTX) Concept: A New Approach for Instant Rehabilitation of Young Children after Avulsion of Central Incisor
}

\author{
Dirk Nolte ${ }^{1,2}$, Claudia Tschammler ${ }^{1,3}$, Markus Henzler ${ }^{4}$, Robert Linsenmann1, \\ Johannes Angermair ${ }^{1}$ \\ ${ }^{1}$ Clinic for Oral and Maxillofacial Surgery, Munich, Germany \\ ${ }^{2}$ Ruhr-University of Bochum, Bochum, Germany \\ ${ }^{3}$ Department of Preventive Dentistry, Periodontology and Cariology, University of Göttingen, Göttingen, Germany \\ ${ }^{4}$ Orthodontic Practice Munich, Munich, Germany \\ Email: dirk.nolte@mkg-muc.com
}

How to cite this paper: Nolte, D., Tschammler, C., Henzler, M., Linsenmann, R. and Angermair, J. (2017) Two-Phase Transplantation (TPTX) Concept: A New Approach for Instant Rehabilitation of Young Children after Avulsion of Central Incisor. Open Journal of Stomatology, 7, 136-146.

https://doi.org/10.4236/ojst.2017.72009

Received: December 31, 2016

Accepted: February 25, 2017

Published: February 28, 2017

Copyright $\odot 2017$ by authors and Scientific Research Publishing Inc. This work is licensed under the Creative Commons Attribution International License (CC BY 4.0).

http://creativecommons.org/licenses/by/4.0/

\begin{abstract}
Background: To present a new idea for rapid management of tooth avulsion in young children and adolescents (age: 6 to 16) by this case report. Case presentation: A nine-year-old boy presented with loss of upper permanent central incisor in early mixed dentition ( 6 to 10 years, phase I). The not yet fully resorbed primary canine was used as tooth transplant for the lost incisor. The intentional renounce on endodontic treatment of the primary transplant permits natural exfoliation of the transplant occurring either spontaneously or due to undermining resorption through the adjacent erupting teeth. In the late mixed dentition (10 to 16 years, phase II), the primary tooth transplant is electively removed and replaced by a premolar autotransplant for long-term rehabilitation of the meanwhile adolescent patient. Results: Primary canine autoTX acts as a temporary denture with instant surgical gap closure. Ensuing premolar autoTX in phase II then acts as permanent denture with excellent 10 years survival rates. Patient satisfaction issued by a questionnaire resulted in good to very good school grades for both phases of autotransplantation. Conclusions: The "TPTX" concept is a new surgical approach that immediately restores the patient's function and aesthetics after tooth loss in early childhood supporting the growth of local bone and soft tissue in the growing adolescent jaw.
\end{abstract}

\section{Keywords}

Autogenous Tooth Transplantation, Premolar, Primary Dentition, 
Resorption, Traumatic Dental Injury (TDI)

\section{Introduction}

The clinical management of traumatic dental injury (TDI) in adolescent dentures still represents a challenge for all fields of dentistry. Over 50\% of all patients suffer from dental trauma before the age of 17 . Up to $10 \%$ of all dental injuries result in loss of a tooth [1] [2]. The prognosis of avulsed and replanted teeth is generally unfavorable with an average five-year survival rate of approximate 50\% [3] [4]. The maximum frequency is between three and four years of age, nine and 12 years of age and again at the age of 16 [5]. Even in adulthood, nearly every third person suffers from renewed TDI. Finally, the prevalence of TDI is about $30 \%$ over the entire lifetime [5] [6].

Since anterior TDI predominantly occurs in both the primary and early mixed dentition (between six and ten years of age) and in the late mixed dentition (10 to 16 years of age), we have developed a concept that allows us to deal with both phases of dentition therefore being designated by us as the "two-phase transplantation" (TPTX) concept (Figure 1). For this purpose, the not yet fully resorbed primary teeth, preferably the primary canines, are used in the primary and early mixed dentition as possible autogenous transplants for replacement of the upper central incisors (phase I: primary (canine) tooth transplantation). The procedure represents a biological approach by the intentional renounce on endodontic treatment, thus basing on the natural exfoliation of the transplanted primary tooth. This approach is therefore temporarily allowing immediate posttraumatic aesthetic rehabilitation of the traumatized patient up to the age of 10 to 16 years which has been proven effective to support both bone and soft tissue growth in the adolescent patient [7] [8].

In the late mixed dentition (phase II, >10 years), when autotransplantation of primary teeth is no longer available or natural exfoliation of primary tooth transplants is to be expected, we apply the well-documented technique of premolar autotransplantation as permanent (lifelong) therapy which has proven successful since many years yielding excellent survival rates [1] [9]-[20].

From the clinical point of view, it is therefore important to differentiate between these two time windows (phase I and II) in regard of the subsequent therapy using either primary tooth and/or premolar transplantation in TDI (Figure $1)$. The novelty of the described concept refers, first, to the intended temporary use of primary tooth transplantion in both primary and early mixed dentition (6 to 12 years) leaving the transplant to its natural exfoliation as a reliable soft tissue and bone co-developing procedure during growth [8] and, secondly, to the sequential follow-up procedure of premolar autotransplantation in late childhood as well-established technique with excellent long-term survival rates.

The technique is described by the clinical case of a nine-year-old boy with traumatic loss of the upper central incisor undergoing the "TPTX" concept. 


\section{Case Report}

A nine year old boy lost the upper right central incisor in a swimming accident and injured the upper left incisor with an uncomplicated crown fracture. The patient presented three months after the accident with the following findings (Figure 2): The clinical situation showed a bony deficit in ridge height and width suggesting loss of the buccal bony wall (Figure 2(A)). The actual orthopan-tomogram (OPG) shows the fractured tooth 11 before removal of the residual root by the local dentist (Figure 2(B)). All four primary canines show significantly reduced root lengths due to the natural exfoliation by the breakthrough of the permanent canines.

On demand of the orthodontist's planning we extracted all four primary canines and decided intraoperatively to use the primary tooth 63 as autotransplant since it exhibited the longest root at this time point. The other three teeth $(53,73,83)$ were stored in a tooth bank as potential reserve teeth. Tooth 63 was then autotransplanted into the defective gap at position 11 according to the technique described below and fixed with a wire-composite semi-rigid splint to the neighbouring tooth 12 for three weeks (Figure 2(C)). Figure 2(D) shows the situation three weeks later directly after removal of the wire-composite splint with one resorbable 4-0 vicryl suture still left in situ.

The primary tooth transplant 63 remained functional in situ for $4 \frac{1}{2}$ years until the patient's age of $13 \frac{1}{2}$ years. Figure 3 shows the postoperative radiological and clinical findings one year (A and C) and 4.5 years (B and D) after transplantation, respectively. The exfoliation of the root did not make significant progress over time, which may be attributed to the lack of an erupting upper adjacent tooth. Meanwhile the natural breakthrough of the permanent canines had taken

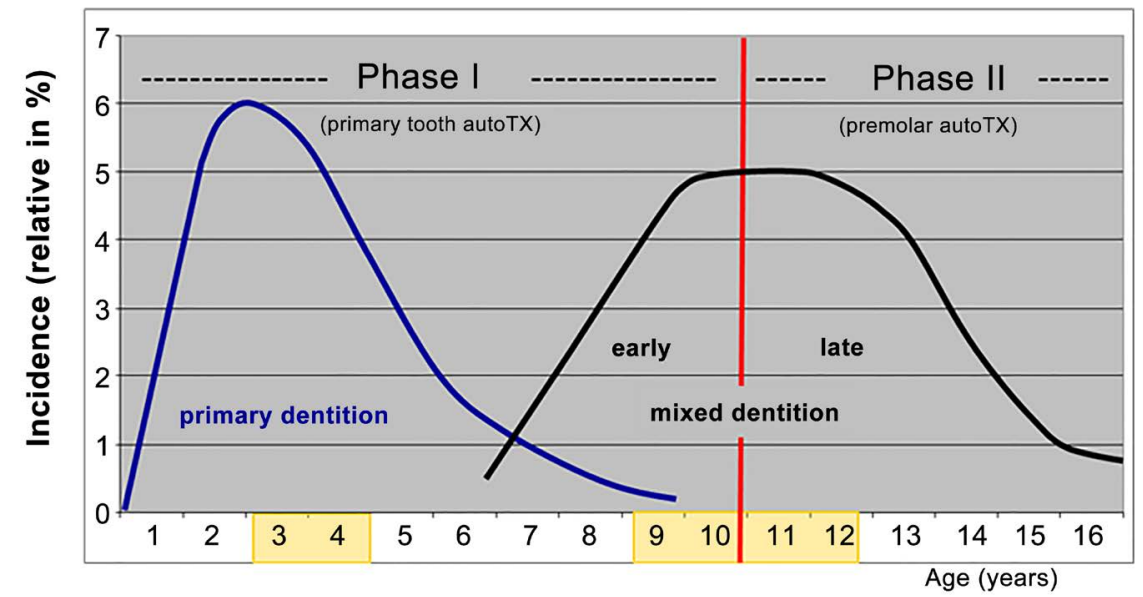

Figure 1. Two-phase transplantation concept ("TPTX" concept) taking into account the peak incidence of occurrence of TDI in childhood and adolescence (schematic). Left of the red line comprises phase I in which primary (canine) tooth autotransplantation (autoTX) is recommended as the preferred temporary therapy, right of the red line indicates phase II in which premolar autotransplantation is recommended as permanent (lifelong) therapy. Highlighted in yellow are the age sections with the greatest statistical risk of suffering tooth trauma in Germany. 

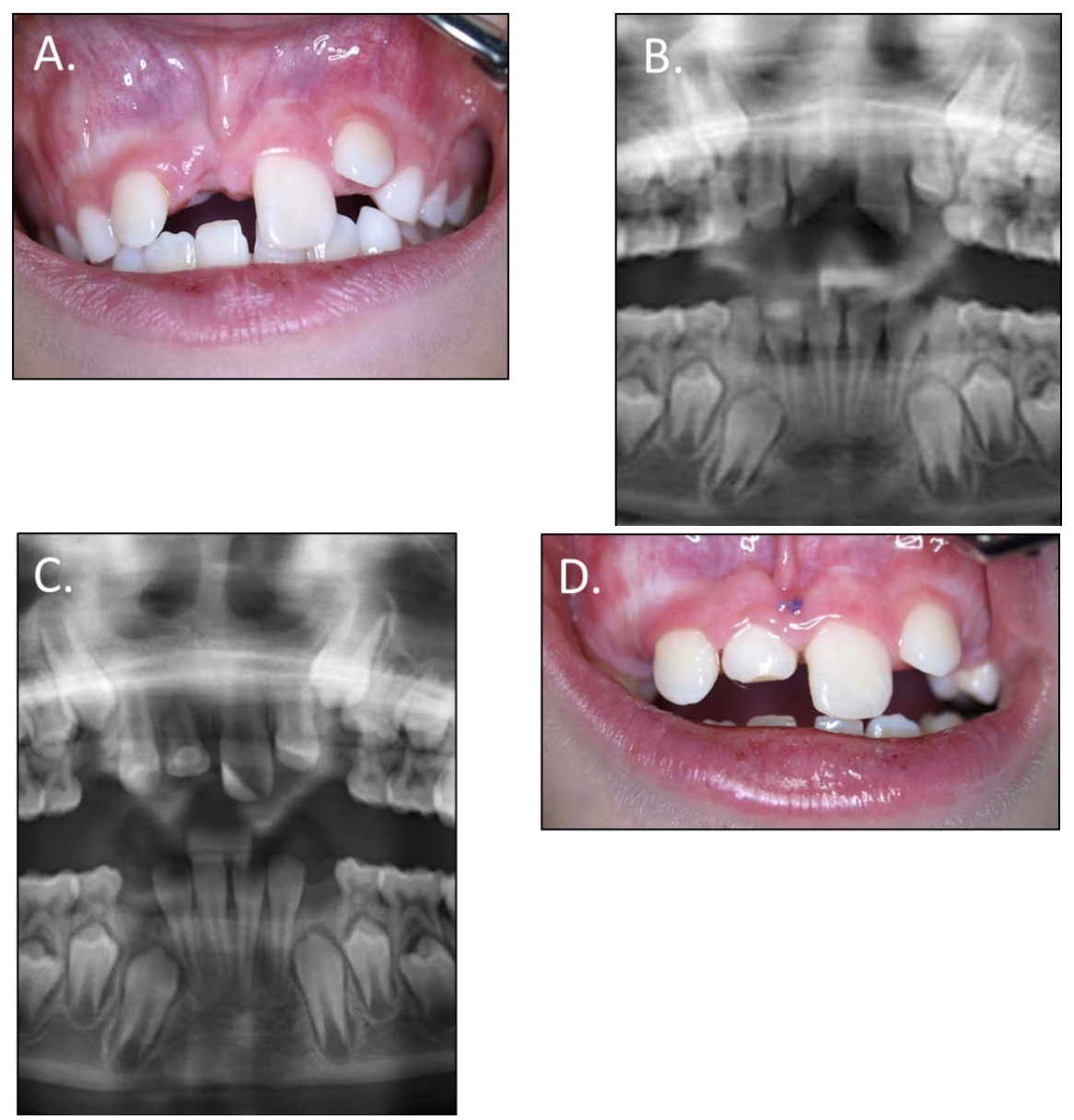

Figure 2. Clinical case of nine year old boy after avulsion and loss of tooth 11 associated with uncomplicated crown fracture of tooth 21 after swimming accident three months ago. (A) Post-traumatic clinical situation with tooth gap in region 11 with evidence of vertical and horizontal bone deficit. The crown fracture of tooth 21 was treated with a corner structure made of composite. (B) Post-traumatic OPG (foreign) with deeply fractured tooth 11 and crown fracture 21 (not yet restored). Fractured root of tooth 11 here still in situ has later been removed by the local dentist. All primary canines show already significant resorption of their roots to approximately $50 \%$ of total length. (C) Postoperative OPG directly after autogenous transplantation of primary canine $63 \rightarrow 11$. The semi-rigid wire-composite splint on the tooth is visible on teeth 11 and 12 , the transplant is placed in clear infraposition. The corner structure of tooth 21 is visible. Note the already marked reduction of root length of the transplanted tooth 63. (D) Clinical situation three weeks after autoTX $63 \rightarrow 11$ and splint removal. One resorbable suture is still in situ.

place (Figure $3(\mathrm{C})$ ). No aesthetic or functional deficiency is notable, vertical bone growth appears good which is reflected by an even overshooting projection of the gingival margin at the trauma site 11 relative to the healthy adjacent tooth 21 (Figure 3(C) and Figure 3(D)). Aesthetic correction of the primary canine with adhesive composite filling or bleaching was neither desired by the patient nor his parents since they were happy with the present situation. The psychological component of this immediate aesthetic rehabilitation cannot be estimated high enough. The patient did not suffer from pain or discomfort at any time. 
The transplant showed no mobility and was fully functional. Root canal treatment with $\mathrm{Ca}(\mathrm{OH})_{2}$ was not necessary at any time. At the age of 13.5 years, the patient presented again at the clinic for decision-making of the consecutive therapy.

In consultation with the treating orthodontist, we enrolled the patient in phase II of the "TPTX" concept by applying premolar autotransplantation. Due to the gnathological situation, the orthodontist decided to use tooth 25 as transplant in region 11 . Figure $4 \mathrm{~A}$ shows the postoperative $\mathrm{x}$-ray of the patient after autoTX $25 \rightarrow 11$ on the day of surgery: The primary canine transplant was electively extracted and the premolar 25 was transplanted after preparation and extension of the alveolar pocket in region 11 . The transplant was fixed to the orthodontic bow with a composite and the soft tissue was adapted by two mattress sutures (Figure 4(B)). During the operation it turned out that the premolar was twin-rooted, which significantly complicated its positioning in region 11 intraoperatively. To avoid interfering occlusal contacts, the tooth was placed in slight infraposition so that subsequent orthodontic rotation and extrusion of the tooth could be performed undisturbedly. The transplant itself was
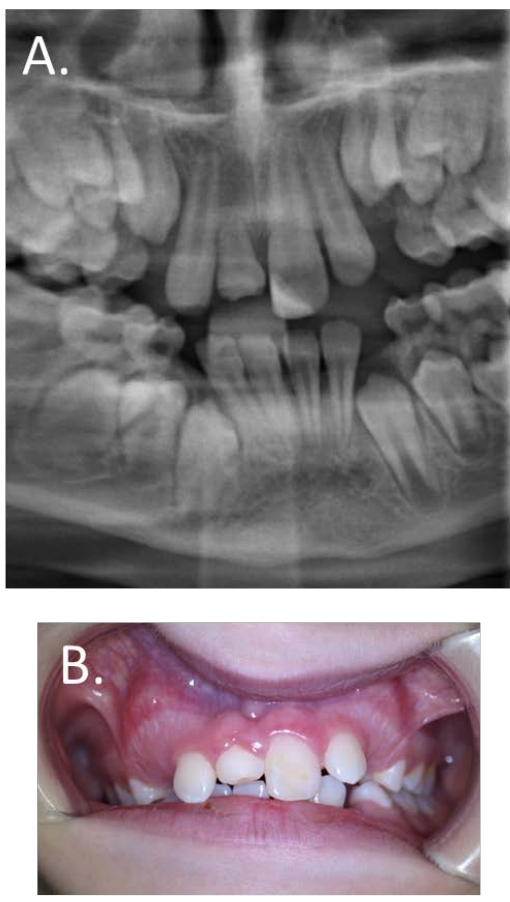

1 years post-OP
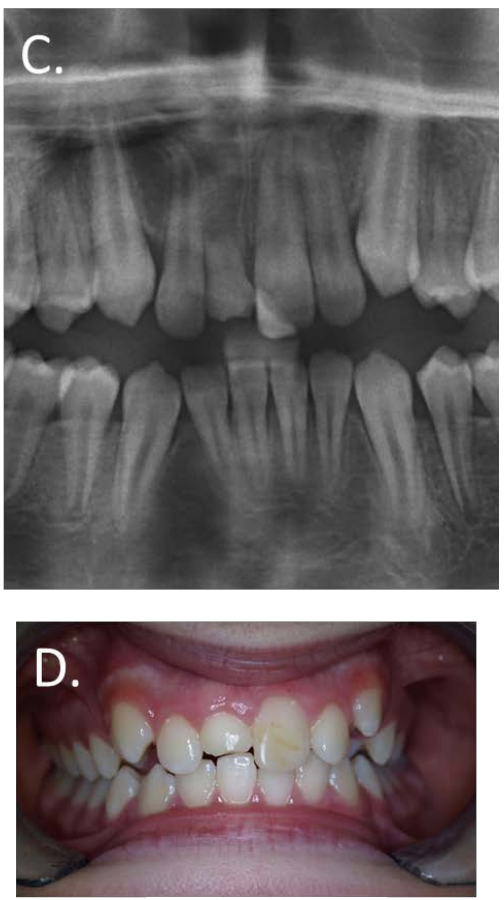

$4 \frac{1}{2}$ years post-OP

Figure 3. Radiological and clinical findings of bone and soft tissue growth in region 11 over the course of 4.5 years (phase I of "TPTX" concept). (A) Radiological and B. clinical findings one year post-TX $63 \rightarrow 11$. (C) Radiological and (D) clinical findings 4.5 years later. Over the course of 4.5 years, the co-development of the alveolar process and soft tissue in region 11 is clearly visible. The contemporary breakthrough of the neighbouring teeth $13,12,22,23$ is to be seen in (C) and (D). The partial resorption of the root of the primary canine in position 11 documents the biological behavior of the transplant. Ankylosis with vertical growth inhibition is not visible as indicated by the maintenance of vertical soft tissue growth towards the incisal edge as compared to healthy tooth 21 . 

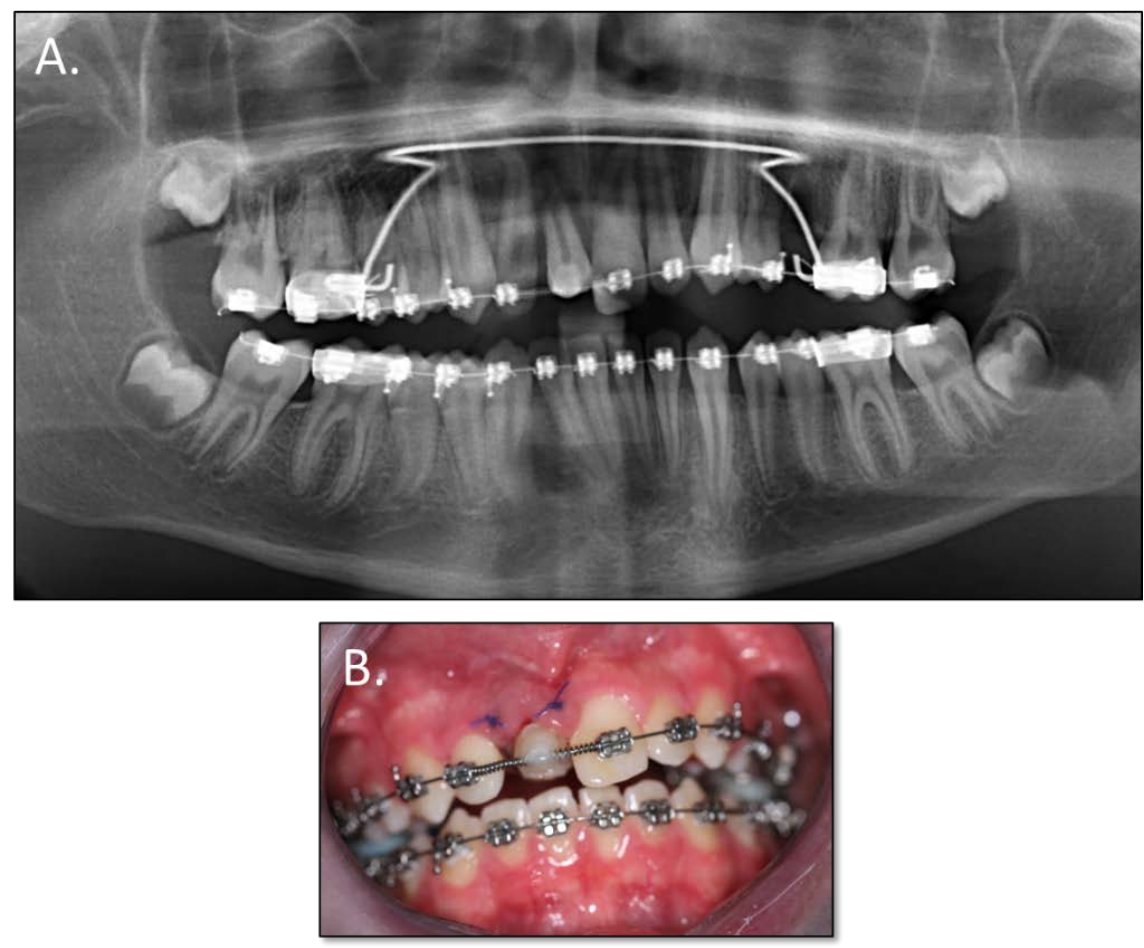

Figure 4. Radiological (A) and clinical (B) situation of the meanwhile 14 years old boy directly after premolar autotransplantation $25 \rightarrow 11$ (phase II of "TPTX" concept). The primary canine tooth transplant was extracted and premolar 25 was transplanted in position 11 . The empty extraction socket in regio 25 is visible. To avoid interfering occlusal contacts the tooth was positioned in infraposition for subsequent rotation and extrusion by the orthodontist. The transplant was fixed with composite to the orthodontic bow, the mucosal flap was readapted by two vertical mattress sutures.

bracketed by the orthodontist three weeks after removing the composite fixture from the orthodontic bar and left in this position for another three weeks without active movement. Six weeks after surgery the orthodontist was allowed to start with gradual rotation of the palatal cusps out of the occlusal contact of the opposing teeth. Figures 5(A)-5(C) show the stepwise change of transplant position three and 12 months after surgery. Figure 6 shows the final result after removal of the orthodontic banding. The premolar transplant has meanwhile been built up in composite adhesive technique. There is a substantial win of soft tissue height on the transplant side (tooth 11) as compared to the left upper incisor with the "uncomplicated" crown fracture (tooth 21). Tooth 11 shows a normal cold sensitivity and percussion testing while the left upper incisor with uncomplicated crown fracture shows normal cold testing, but abnormal percussion testing suggesting partial ankylosis (substitution resorption) as indicated by the tendency to buccal gingival recession.

The mean grade of satisfaction issued by a questionnaire given by this patient and his parents was 1.4 consisting of the following measurements: expectations of OP fulfilled: grade 2.0 (good); success of OP: grade 1.0 (very good); aesthetic result: grade 2.0 ; early postoperative pain: grade 1.0 ; late postoperative compla- 

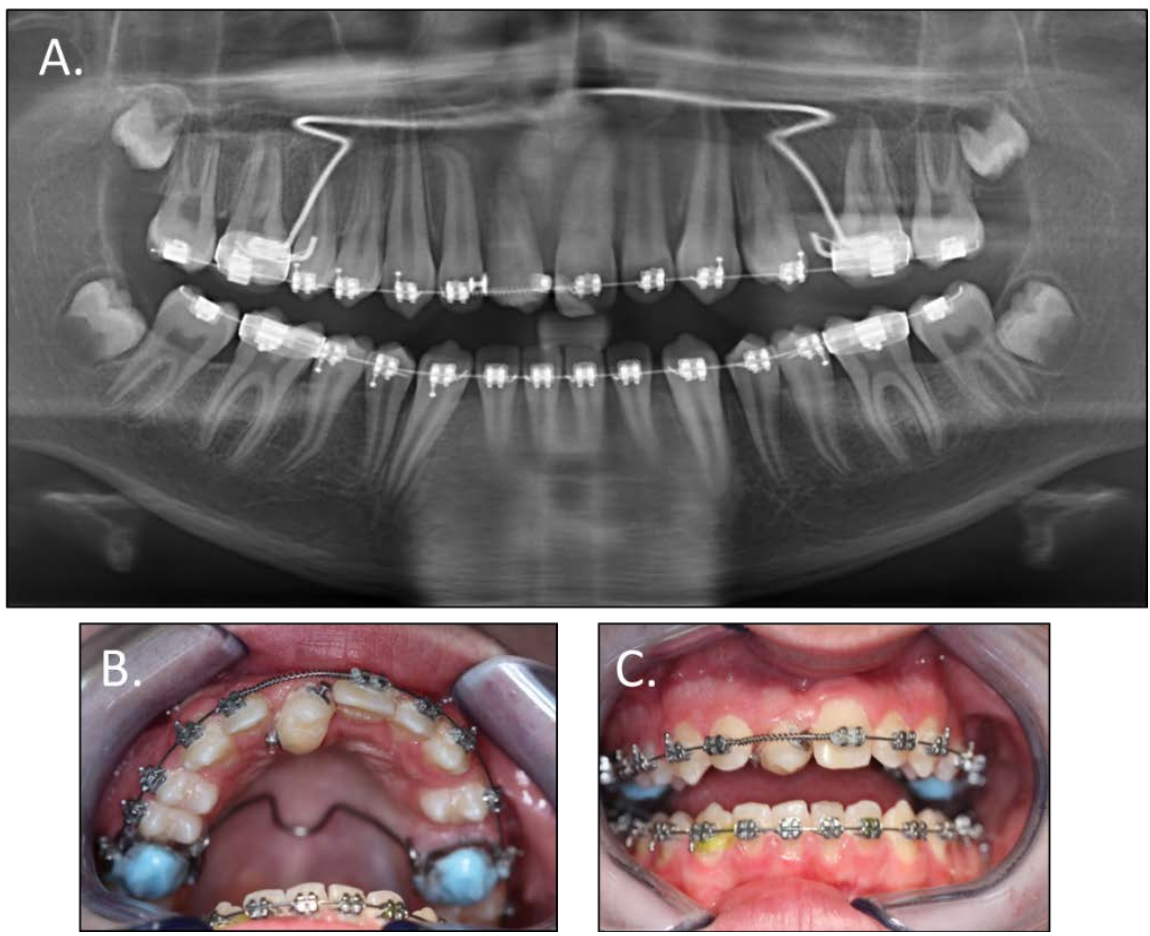

Figure 5. Radiological and clinical course three (A) and (B) and 12 (C) months after premolar autotransplantation $25 \rightarrow 11$ (phase II of TPTX-concept). A. Radiologic and (B) occlusal view three months after autoTX. The transplant has meanwhile been bracketed by the orthodontist to start derotation and extrusion of the transplant. Two brackets have been fixed mesially and distally of the crown to facilitate the rotation of the transplant. (C) Lateral view 12 months after autoTX. The rotation of the transplant has nearly been accomplished.
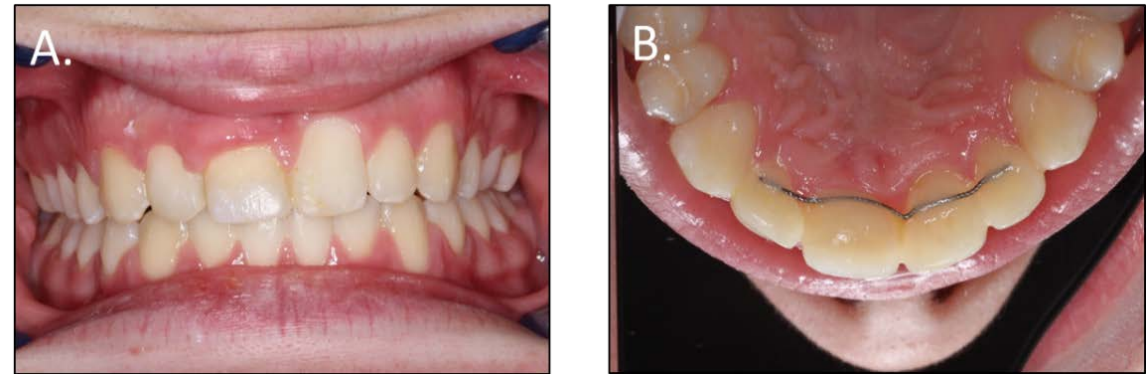

Figure 6. Clinical situation 2.5 years after finishing orthodontic therapy and restauration of autotransplant 11 in composite adhesive technique. Lateral and occlusal (B) views of premolar transplant 11. In the lateral view a clear soft tissue surplus is visible as compared to tooth 21 with uncomplicated crown fracture.

ints: grade 1.0. The questions asked 1) Would you undergo the surgery again? and 2) Would you recommend the surgery to someone else? were both answered with Yes.

\section{Discussion}

The two-phase transplantation concept ("TPTX" concept) represents a new surgical approach that ultimately arose from the absence of therapeutic alternatives 
aiming at a quick and sustainable treatment of traumatic dental injury (TDI) in young children and adolescents. In recent studies from our group, primary tooth transplantation was given a grade of 1.5 (grade 1: very good, grade 6: very bad) [8] and premolar transplantation a grade of 1.7 [22], indicating the high level of satisfaction of both patients and parents with these two forms of autotransplantation. This is well in line with this patient's estimation of the outcome of the "TPTX" concept giving a mean grade of 1.4.

If orthodontic gap closure is a therapeutic alternative, then it represents the first-line therapy. This can, however, only be applied in the late mixed dentition (= phase II of the "TPTX" concept) when dental breakthrough of the permanent teeth has been accomplished, thus ruling out adequate treatment of young patients in primary and early mixed dentition (phase I of "TPTX" concept, Figure 1). The prosthetic treatment often entails a significant psychological burden for these patients and their parents [23] [24]. Moreover, this kind of treatment leads to the serious problem that bone and soft tissue are not adequately co-developed due to the prothesis' counterproductive pressure load on mucosa and bone. Enossal implantation will become a technical challenge for implantologists in patients at the age of 18 after many years of TDI induced edentulism.

For exactly these reasons we have dealt since 2005 with the question of whether the loss of teeth particularly in early childhood (six to 10 years, phase I) with its undesirable sequelae for aesthetics and function can effectively be overcome by autogenous transplantation techniques. These considerations made us develop the "TPTX" concept through which patients can be rehabilitated both in the primary and early mixed dentition at the age between six and 14 years (Figure 1). We have shown that in phase I complications such as pain, swelling and inflammation occurred in none of the cases in a retrospective study with a total of 10 patients with 14 primary canine tooth transplants [8]. In all cases, bone and soft tissue growth was effectively co-developed as has been quantitatively assessed. We know so far of no therapy in the current literature that uses the natural exfoliation of transplanted primary teeth for the induction of local bone and soft tissue growth. The technique permits reliable and immediate prosthetic, aesthetic and functional rehabilitation of the young patients (Figure $2(\mathrm{~A}))$ which is associated with high acceptance by patients and parents [8].

Other research groups have set their treatment goal of transplanting primary canines as permanent dental supply in the traumatized region of the maxilla [7]. This is accomplished by using retrograde alloplastic posts prepared during the operation for mechanical stabilization of the primary tooth transplant. This auto-alloplastic concept seems more attractive for the patient at first sight since it spares him or her a second intervention. The use of alloplastic posts may however bear a potential danger for growth inhibition of the jawbones in young children. Precisely for this reason we have chosen the concept of natural exfoliation of the primary tooth transplants by renouncing on dental filling materials if possible. 
Autotransplantation of primary (canine) teeth does not necessarily require root canal filling of the transplant which makes the procedure considerably easier and shorter in time. Only in the event of an inflammatory complication is it necessary to fill the tooth with $\mathrm{Ca}(\mathrm{OH})_{2}$ thus allowing further physiological resorption [21]. Aiming at the natural resorption of the primary tooth transplants, we recommend to use only resorbable root canal fillings.

If the young patients with TDI successfully pass phase I of the "TPTX" concept and reach 10 to 14 years of age, the intervention can be regarded as success according to our understanding. Thereafter, we recommend our patients ensuing autogenous premolar transplantation (phase II) as a well-established and successful longterm therapy [1] [9]-[20] as shown in this case report. The technique of premolar transplantation provides excellent long-term results compared to other prosthetic or implantologic procedures under the circumstances of TDI [1].

\section{Conclusion}

The "TPTX" concept represents a new surgical approach that allows immediate restoration of the patient's function and aesthetics after tooth loss in early childhood supporting the growth of local bone and soft tissue in the growing adolescent jaw. The patients' and parents' estimation of the concept appears very promising and therefore suggests its application under these particular circumstances of traumatic dental injury.

\section{Ethical Approval}

This study was approved by the ethical committee of the Bavarian Medical Association of Munich, number 13116/2013. We confirm that the guidelines of this study have followed the Declaration of Helsinki. Informed consent of the patient has been obtained before publication.

\section{Conflict of Interest}

The corresponding author confirms that no conflict of interest exists for himself or his/her co-authors.

\section{Acknowledgements}

We would like to thank Ms. Sabine Liebing for typing the manuscript. We would also like to thank Mr. Florian Feller for his technical assistance in preparing the graphics.

\section{References}

[1] Andreasen, J.O., Schwartz, O., Kofoed, T. and Daugaard-Jensen, J. (2009) Transplantation of Premolars as an Approach for Replacing Avulsed Teeth. Pediatric Dentistry, 31, 129-132.

[2] Bae, J.H., Choi, Y.H., Cho, B.H., Kim, Y.K. and Kim, S.G. (2010) Autotransplantation of Teeth with Complete Root Formation: A Case Series. Journal of Endodon- 
tics, 36, 1422-1426. https://doi.org/10.1016/j.joen.2010.04.028

[3] Andreasen, F.M. and Pedersen, B.V. (1985) Prognosis of Luxated Permanent Teeth-The Development of Pulp Necrosis. Endodontics \& Dental Traumatology, 1, 207-220. https://doi.org/10.1111/j.1600-9657.1985.tb00583.x

[4] Pohl, Y., Wahl, G., Filippi, A. and Kirschner, H. (2005) Results after Replantation of Avulsed Permanent Teeth. III. Tooth Loss and Survival Analysis. Dental Traumatology, 21, 102-110. https://doi.org/10.1111/j.1600-9657.2004.00299.x

[5] Glendor, U. (2008) Epidemiology of Traumatic Dental Injuries-A 12 Year Review of the Literature. Dental Traumatology, 24, 603-611.

https://doi.org/10.1111/j.1600-9657.2008.00696.x

[6] Glendor, U. (2009) Aetiology and Risk Factors Related to Traumatic Dental Injuries-A Review of the Literature. Dental Traumatology, 25, 19-31. https://doi.org/10.1111/j.1600-9657.2008.00694.x

[7] Pohl, Y., Geist, P. and Filippi, A. (2008) Transplantation of Primary Canines after Loss or Ankylosis of Upper Permanent Incisors. A prospective Case Series Study on Healing and Survival. Dental Traumatology, 24, 388-403. https://doi.org/10.1111/j.1600-9657.2008.00563.x

[8] Tschammler, C., Angermair, J., Linsenmann, R., Heiligensetzer, M. and Nolte, D. (2014) Primary Canine Auto-Transplantation-A New Surgical Technique. Oral Surgery, Oral Medicine, Oral Pathology, Oral Radiology, 119, 158-169. https://doi.org/10.1016/j.oooo.2014.07.003

[9] Slagsvold, O. and Bjercke, B. (1978) Applicability of Autotransplantation in Cases of Missing Upper Anterior Teeth. American Journal of Orthodontics, 74, 410-421. https://doi.org/10.1016/0002-9416(78)90063-5

[10] Slagsvold, O. and Bjercke, B. (1978) Indications for Autotransplantation in Cases of Missing Premolars. American Journal of Orthodontics, 74, 241-257. https://doi.org/10.1016/0002-9416(78)90201-4

[11] Andreasen, J.O., Paulsen, H.U., Yu, Z., Ahlquist, R., Bayer, T. and Schwartz, O. (1990) A Long-Term Study of 370 Autotransplanted Premolars. Part I. Surgical Procedures and Standardized Techniques for Monitoring Healing. European Journal of Orthodontics, 12, 3-13. https://doi.org/10.1093/ejo/12.1.3

[12] Andreasen, J.O., Paulsen, H.U., Yu, Z. and Bayer, T. (1990) A Long-Term Study of 370 Autotransplanted Premolars. Part IV. Root Development Subsequent to Transplantation. European Journal of Orthodontics, 12, 38-50. https://doi.org/10.1093/ejo/12.1.38

[13] Andreasen, J.O., Paulsen, H.U., Yu, Z., Bayer, T. and Schwartz, O. (1990) A LongTerm Study of 370 Autotransplanted Premolars. Part II. Tooth Survival and Pulp Healing Subsequent to Transplantation. European Journal of Orthodontics, 12, 1424. https://doi.org/10.1093/ejo/12.1.14

[14] Andreasen, J.O., Paulsen, H.U., Yu, Z. and Schwartz, O. (1990) A Long-Term Study of 370 Autotransplanted Premolars. Part III. Periodontal Healing Subsequent to Transplantation. European Journal of Orthodontics, 12, 25-37. https://doi.org/10.1093/ejo/12.1.25

[15] Josefsson, E., Brattstrom, V., Tegsjo, U. and Valerius-Olsson, H. (1999) Treatment of Lower Second Premolar Agenesis by Autotransplantation: Four-Year Evaluation of Eighty Patients. Acta Odontologica Scandinavica, 57, 111-115. https://doi.org/10.1080/000163599429002

[16] Czochrowska, E.M., Stenvik, A., Album, B. and Zachrisson, B.U. (2000) Autotransplantation of Premolars to Replace Maxillary Incisors: A Comparison with Natural 
Incisors. American Journal of Orthodontics and Dentofacial Orthopedics, 118, 592 600. https://doi.org/10.1067/mod.2000.110521

[17] Plakwicz, P., Wojtowicz, A. and Czochrowska, E.M. (2013) Survival and Success Rates of Autotransplanted Premolars: A Prospective Study of the Protocol for Developing Teeth. American Journal of Orthodontics and Dentofacial Orthopedics, 144, 229-237. https://doi.org/10.1016/j.ajodo.2013.03.019

[18] Day, P. and Duggal, M. (2008) Autotransplantation for Failing and Missing Anterior Teeth. Pediatric Dentistry, 30, 286-287.

[19] Day, P.F., Kindelan, S.A., Spencer, J.R., Kindelan, J.D. and Duggal, M.S. (2008) Dental Trauma: Part 2. Managing Poor Prognosis Anterior Teeth-Treatment Options for the Subsequent Space in a Growing Patient. Journal of Orthodontics, 35, 143-155. https://doi.org/10.1179/146531207225022590

[20] Waldon, K., Barber, S.K., Spencer, R.J. and Duggal, M.S. (2012) Indications for the Use of Auto-Transplantation of Teeth in the Child and Adolescent. European Archives of Paediatric Dentistry, 13, 210-216. https://doi.org/10.1007/BF03262872

[21] Nolte, D., Linsenmann, R. and Huth, K.C. (2011) Autogene Zahntransplantation: Neue Perspektiven. $M K G$-Chirurg, 4, 92-101.

https://doi.org/10.1007/s12285-010-0205-Z

[22] Huth, K.C., Nazet, M., Paschos, E., Linsenmann, R., Hickel, R. and Nolte, D. (2013) Autotransplantation and Surgical Uprighting of Impacted or Retained Teeth: A Retrospective Clinical Study and Evaluation of Patient Satisfaction. Acta Odontologica Scandinavica, 71, 1538-1546.

https://doi.org/10.3109/00016357.2013.775667

[23] Oka, A.E., N'Cho, K.J. and Bakayoko-Ly, R. (2003) Replacement of Deciduous Incisors in Children: Psychological Aspects. Odontostomatol Trop, 26, 30-36.

[24] Antunes, L.S., Debossan, P.F., Bohrer, L.S., Abreu, F.V., Quintanilha, L.E. and Antunes, L.A. (2013) Impact of Traumatic Dental Injury on the Quality-of-Life of Children and Adolescents: A Case-Control Study. Acta Odontologica Scandinavica, 71, 1123-1128. https://doi.org/10.3109/00016357.2012.750011

\section{Scientific Research Publishing}

Submit or recommend next manuscript to SCIRP and we will provide best service for you:

Accepting pre-submission inquiries through Email, Facebook, LinkedIn, Twitter, etc. A wide selection of journals (inclusive of 9 subjects, more than 200 journals)

Providing 24-hour high-quality service

User-friendly online submission system

Fair and swift peer-review system

Efficient typesetting and proofreading procedure

Display of the result of downloads and visits, as well as the number of cited articles

Maximum dissemination of your research work

Submit your manuscript at: http://papersubmission.scirp.org/

Or contact ojst@scirp.org 